\title{
The role of contingency awareness in single-cue human eyeblink conditioning
}

\author{
Gabrielle Weidemann, ${ }^{1,3}$ Erin Best, ${ }^{1}$ Jessica C. Lee, ${ }^{2}$ and Peter F. Lovibond ${ }^{2}$ \\ ${ }^{1}$ School of Social Sciences and Psychology, University of Western Sydney, Sydney, 2751, Australia; ${ }^{2}$ School of Psychology, University \\ of New South Wales, Sydney, 2052, Australia
}

\begin{abstract}
Single-cue delay eyeblink conditioning is presented as a prototypical example of automatic, nonsymbolic learning that is carried out by subcortical circuits. However, it has been difficult to assess the role of cognition in single-cue conditioning because participants become aware of the simple stimulus contingency so quickly. In this experiment $(n=166)$, we masked the contingency to reduce awareness. We observed a strong relationship between contingency awareness and conditioned responding, with both trace and delay procedures. This finding suggests that explicit associative knowledge and anticipatory behavior are regulated by a coordinated system rather than by functionally and neurally distinct systems.
\end{abstract}

[Supplemental material is available for this article.]

It is often claimed that Pavlovian conditioning is mediated by a functionally and neurally distinct system that developed early in evolution and has been preserved in humans. This system is considered to be independent of the cognitive system that underpins reasoning, language, and explicit "declarative" learning (e.g., Schacter and Tulving 1994; Squire 1994; Eichenbaum and Cohen 2001). Although several variations of this approach have been proposed in the learning and memory literature, they will collectively be referred to as the "dual-system" model. The principal alternative is a single system model in which one integrated learning system gives rise to both conscious declarative knowledge and conditioned behavior (e.g., Mitchell et al. 2009). The predictions of the dual-system model can be seen clearly in the case of eyeblink conditioning, often considered to be a prototypical Pavlovian procedure (Squire 1987).

In human eyeblink conditioning, a conditioned stimulus (CS) such as a tone is paired with an unconditioned stimulus (US), usually an airpuff to the eye. After several pairings, the CS acquires the ability to elicit anticipatory eyeblink responses (conditioned responses, CRs). In differential conditioning, a second CS, such as white noise, is presented in the absence of the US in order to provide a within-participant control. In addition to recording eyeblink responses, it is also possible to assess the conscious, explicit knowledge acquired by participants. The dual-system model predicts that CRs will develop regardless of whether the participant has explicit awareness of the contingency between the CS and the US. It also predicts that cognitive load or misleading instructions will selectively impair the cognitive system but leave the conditioning system, and hence CRs, largely unaffected.

The strongest evidence for the dual-system model comes from research carried out by Squire's group. Clark and Squire $(1998,1999)$ and Smith et al. (2005) found that participants classified as unaware of a differential contingency in a post-experimental questionnaire nonetheless showed differential eyeblink CRs. However, they only observed this pattern when they used a delay conditioning procedure, in which the CS and US overlap in time. Participants conditioned with a trace procedure, in which there is a short (500-1000 msec) period between CS offset and US

\section{${ }^{3}$ Corresponding author}

E-mail G.Weidemann@uws.edu.au

Article is online at http://www.learnmem.org/cgi/doi/10.1101/Im.029975.112. onset, only showed differential CRs if they also showed contingency awareness. Clark and Squire $(1998,1999)$ and Smith et al. (2005) interpreted this pattern, together with relevant animal and human neural evidence, to mean that delay eyeblink conditioning is a form of unconscious nondeclarative memory carried out by a subcortical circuit involving the cerebellum and brainstem. By contrast, they argued that the temporal gap in trace conditioning means that it cannot be learned by the nondeclarative system; instead, it is processed by the conscious declarative memory system, which involves the hippocampus and medial temporal lobe.

Although the data from Squire's group are striking, the same results have not typically been obtained by other groups, who find, instead, that both delay and trace conditioning are restricted to participants classified as contingency aware (Nelson and Ross 1974; Perry et al. 1977; Benish and Grant 1980; Knuttinen et al. 2001; Lovibond et al. 2011; Weidemann and Antees 2012). In response to these disparate results, Manns et al. (2002) have argued that differential eyeblink conditioning, even with a delay procedure, might sometimes require involvement of the declarative hippocampal system. They suggest that a purer example of nondeclarative (unconscious) conditioning is provided by the single-cue design, in which there is only a single CS paired with the US, and no within-participant control CS.

However, there are two features of single-cue eyeblink conditioning that make it challenging to investigate the role of awareness. First, the contingency is so easy to learn that almost all participants become aware of it early in training, even under cognitive load (Ross 1971). Second, the absence of a control stimulus makes it difficult to determine the component of eyeblink responding that is associative in nature, that is, due to the CS-US pairing. Nonetheless, there is some evidence that single-cue delay conditioning might be partially independent of awareness. Papka et al. (1997) found that a post-experimental assessment of awareness was not related to CR production in a single-cue delay conditioning paradigm, and Manns et al. (2001) showed that early contingency awareness (assessed after 10 conditioning trials) predicted subsequent eyeblink responding in trace but not delay conditioning.

Given the discrepancy between the single-cue conditioning results and the differential conditioning results reviewed above, we wished to further investigate the role of contingency 
awareness in single-cue eyeblink conditioning. In order to reduce contingency awareness, we used a masking task that we had previously used in differential conditioning (Weidemann and Antees 2012), based on a procedure pioneered by Dawson and Biferno (1973) in electrodermal conditioning. We also included the online button-press measure of US expectancy previously employed by Perry et al. (1979) and Manns et al. (2000b).

Participants were given a cover story that described the experiment as an investigation of auditory perception. On each trial, a series of spoken letters was presented at differing volumes, followed by a tone CS. Participants were asked to match the volume of the tone to one of the letters. The cover story also included a (misleading) explanation of the purpose of the airpuff, the eyeblink conditioning apparatus, and the button-press expectancy response (Weidemann and Antees 2012; Supplemental Material). The 166 undergraduate student participants (122 female, mean age $=21.0 \mathrm{yr}$ ) received $50 \mathrm{CS}-\mathrm{US}$ trials, 25 US-alone trials, and 25 blank trials in which no stimuli were presented. US-alone and blank trials, collectively referred to as No-CS trials, were included to further disguise the CS-US contingency and to provide a comparison for eyeblink responses made on CS trials. There was nothing to signal the occurrence of the blank trials or the US-alone trials. Participants were randomly allocated to the two conditioning groups (Delay: $n=82$; Trace: $n=84$ ). Figure 1 shows the timing of the CS and the US and the CR interval in the Delay and the Trace conditions. Following conditioning, all participants were given the post-experimental questionnaire that was used by Manns et al. (2000a).

The mean score on the Manns et al. (2001) questionnaire was 3.61 for the Delay group and 3.81 for the Trace group (out of five questions-two of the original seven questions were excluded from consideration because the inclusion of US-alone trials rendered these questions ambiguous, $t_{(164)}=-0.787, P=0.432$ twotailed [see Supplemental Material for details]). Across all participants, $47.0 \%$ scored $5,21.7 \%$ scored $4,9.0 \%$ scored $3,8.4 \%$ scored $2,5.4 \%$ scored 1 , and $8.4 \%$ scored 0 . To examine eyeblink conditioning as a function of awareness, we set a threshold score of 4 to define awareness. That is, participants who scored 4 or higher were classified as aware, whereas participants who scored 3 or lower were classified as unaware.

Figure 2 shows mean percent eyeblink responses measured on CS trials and No-CS trials as a function of trial blocks, separated

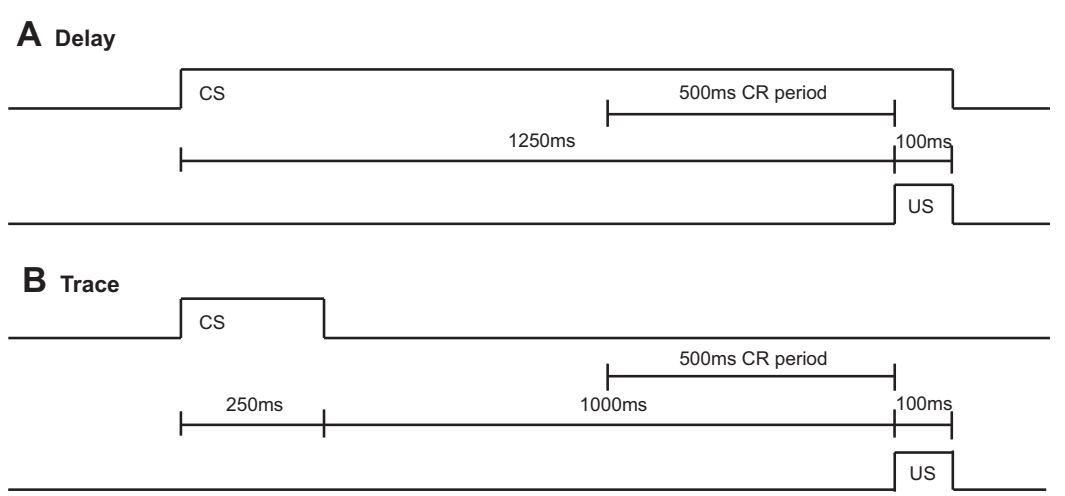

Figure 1. Temporal parameters used for conditioning. $(A)$ In the Delay group, the CS was presented for $1350 \mathrm{msec}$, overlapping and coterminating with the 100-msec US. (B) In the Trace group, the CS was presented for $250 \mathrm{msec}$, followed by a 1000 -msec trace interval, followed by the 100 -msec US. The inter-stimulus interval was therefore $1250 \mathrm{msec}$ for both groups. Each trial was separated from the next with an inter-trial interval (ITI) of 10-15 sec. An eyeblink was scored as a CR if it occurred in the 500-msec time interval before onset of the US, or in the equivalent period on blank trials. In addition, the amplitude of the blink had to be at least $20 \%$ of that participant's unconditioned blink amplitude in response to the first five US presentations of the conditioning session. by Awareness and Conditioning procedure. Averaged over Conditioning procedure and blocks, participants emitted more eyeblinks on CS than on No-CS trials, as shown by the main effect for Trial Type, $F_{(1,162)}=30.69, P<0.05$. There was also an interaction between Trial type and linear trend over trial blocks, $F_{(1,162)}=$ 7.53, $P<0.05$, demonstrating that eyeblinks to the CS increased over blocks relative to No-CS responding. There was no interaction between Trial Type and Conditioning procedure, $F<1$. However, conditioning was stronger in Aware participants, as shown by a significant interaction between Trial Type and Awareness, $F_{(1,162)}=6.73, P<0.05$. Importantly, the triple interaction with Conditioning procedure was not significant, $F<1$, confirming that the relationship between conditioning and awareness was present in both the Delay and Trace groups.

Among the Aware participants, there was a main effect for Trial type, $F_{(1,112)}=49.35, P<0.05$, and an interaction between Trial Type and linear trend over blocks, $F_{(1,112)}=11.80, P<$ 0.05. Neither of these contrasts interacted with Conditioning procedure, $F_{(1,122)}=1.06, P>0.05$ and $F_{(1,112)}=2.66, P>0.05$, respectively. In the Unaware participants, there was a near significant main effect for Trial Type, $F_{(1,50)}=3.85, P=0.055$, but no significant interaction with linear trend over blocks, $F_{(1,50)}=$ $1.08, P>0.05$, or Conditioning procedure, $F<1$.

It is possible that the near significant eyeblink conditioning observed in the Unaware groups was due to some aware or partially aware participants having been incorrectly classified as unaware. To test this possibility, we repeated all of the above analyses using a more liberal criterion for awareness (i.e., a stricter criterion for unawareness). We classified participants who scored 3 or above as Aware, and those who scored 2 or less as Unaware. The analysis generated a similar pattern of results to that observed with the original criterion. However, when tested separately, the naware participants showed no consistent difference in blinking to the CS relative to No-CS, $F_{(1,35)}=1.17, P>0.05$, and again there was no interaction with Conditioning procedure, $F<1$. With the stricter criterion to classify participants as unaware there was a decrease in the $F$ ratio which demonstrates that the difference in responding between CS and No-CS trials is smaller with the stricter criterion, and would not approach significance even with greater power. This pattern is consistent with the idea that the liberal criterion wrongly classified some aware participants as unaware, and that these participants were responsible for the observed conditioning. Although the criteria used for defining awareness are always somewhat arbitrary, the data are clear in showing stronger conditioning in aware than in unaware participants, a pattern that cannot be attributed to the choice of awareness criteria or statistical power.

The advantage of recording online US expectancy is that it is possible to estimate a point within the session when aware participants first demonstrated their knowledge of the CS-US contingency (Weidemann and Antees 2012; Supplemental Material). We were able to define a point of awareness for 79 participants (35 from the Delay group and 44 from the Trace group). We then examined conditioned eyeblink responses before and after this point. Figure 3 shows button-press expectancy responses and eyeblink CRs on a trial-by-trial basis, aligned around the point of awareness for each individual participant (trial 1). 

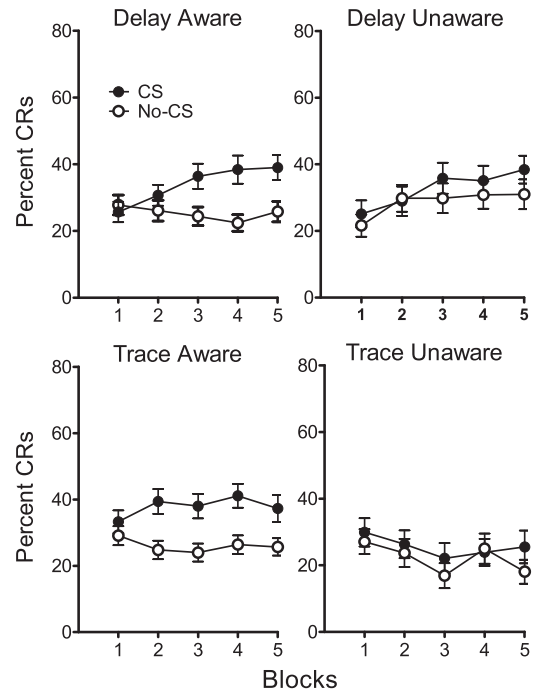

Figure 2. Mean percentage of eyeblink conditioned responses (CRs) made on CS trials and on No-CS (control) trials over the five blocks of 20 trials. Each block of 20 trials included exactly 10 conditioning trials, five blank trials, and five US-alone trials. The three different trial types were presented in random order, except for the restrictions that there could be no more than three conditioning trials in a row and no more than two blank or US-alone trials in a row. Data are presented separately for participants classified as aware (left panels) and unaware (right panels) of the CS-US contingency by post-experimental questionnaire. Data for participants in the Delay conditioning group are shown in the upper panels and data for participants in the Trace conditioning group are shown in the lower panels.

In the contrast analysis there were again no significant effects involving the Conditioning procedure (Trace vs. Delay; largest $\left.F_{(1,77)}=2.20, P>0.05\right)$, so the data in Figure 3 are averaged over this factor. The upper panel of Figure 3 displays the percentage of participants who made a button-press response on each trial. The clear emergence of button pressing during the CS at trial 1 is a necessary consequence of the way in which the point of awareness was defined.

The bottom panel of Figure 3 displays the percentage of participants who showed an eyeblink CR on each trial. Although these data are quite variable on a trial-by-trial basis, it can be seen that participants tended to blink more to the CS relative to No-CS after the point of awareness, compared to before. Averaged over the pre- and post-periods, there was a main effect for Stimulus type: Participants showed more eyeblink CRs on CS than No-CS trials, $F_{(1,75)}=30.12, P<0.05$. There was also a main effect for the pre-post comparison, reflecting the greater number of CRs after the point of awareness, averaged over Stimulus type, $F_{(1,75)}=7.56, P<0.05$. Critically, the interaction between these two contrasts was significant, $F_{(1,75)}=15.79, P<0.05$, demonstrating that the tendency to blink more on CS than No-CS trials was greater after the point of awareness.

A comparison between CS and No-CS CRs after the point of awareness showed that CRs were much higher to the CS than to No-CS, $F_{(1,75)}=48.72, P<0.05$. Before the point of awareness, there was a tendency for CRs to be higher to the CS than to No-CS, $F_{(1,75)}=3.99, P=0.049$. This could be taken as evidence for pre-aware conditioning. However, as can be seen in the upper panel of Figure 3, there was a similar tendency for slightly greater button-press expectancy to the CS in the pre-awareness period $\left(F_{(1,77)}=9.95, P<0.05\right)$. This trend in both measures may be due to the presence of noise or variability in the button-press data that makes it difficult to define precisely when participants start expecting the US in response to the CS. To provide a stronger test of the impact of awareness on differential eyeblink CRs, we conducted a multi-level modeling analysis that demonstrated significantly greater responding to the CS relative to No-CS as a function of awareness, while controlling for the number of conditioning trials experienced (see Supplemental Material).

The present data demonstrate a clear association between explicit knowledge and conditioned responding in single-cue eyeblink conditioning. The results suggest the importance of cognitive processes for both learning (acquisition of knowledge of the CS-US association) and performance (elicitation of US expectancy and anticipatory responding by the CS). In this regard, the present experiment is consistent with previous research on the role of awareness and expectancy in differential eyeblink conditioning (Lovibond et al. 2011; Weidemann and Antees 2012). Similar data have been observed for other forms of associative learning in humans (for reviews, see Lovibond and Shanks 2002; Mitchell et al. 2009).

The present data have important implications for the search for neural underpinnings of learning and memory. In particular, they suggest that the neural circuits for conditioning and cognition might not be as distinct as implied by dual-system theories. For example, the present data are inconsistent with Clark and Squire's $(1998,1999)$ dual-system hippocampal-cerebellar model in two important ways. First, there was little evidence of conditioning without parallel awareness and, second, there was no difference in the strength of the awareness-conditioning relationship for trace and delay conditioning. Taking the present results

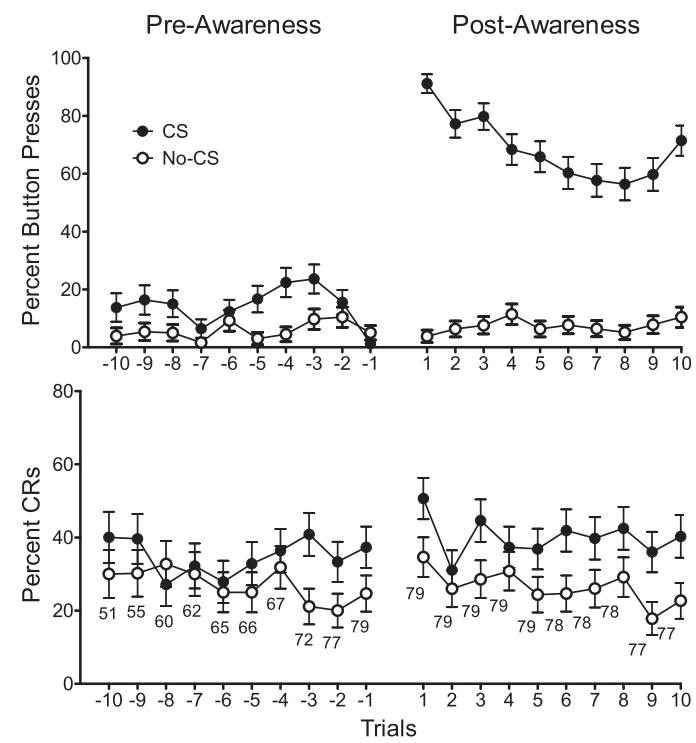

Figure 3. Mean percentage of US-expectancy button presses (upper panels) and eyeblink CRs (lower panels) made on CS and No-CS trials as a function of the development of CS-US contingency awareness. Data are shown for the 10 trials preceding and following the point of awareness $($ trial +1$)$, defined for each individual according to change-point analysis (Taylor 2000). This analysis, which uses a combination of cumulative sum charts and bootstrapping to detect a point of inflection, was applied to button-press responding on successive blocks of two CS and two No-CS trials. The first block during which there was a significant increase in this difference score, according to the change-point analysis, was determined to be the block when awareness developed for that participant. The numbers in the bottom panel next to each trial indicate the number of participants who contributed data on that trial (participants who became aware early may have had fewer than 10 pre-aware trials, whereas participants who became aware late may have had fewer than 10 post-aware trials). 
with the broader literature on the role of cognitive processes in Pavlovian conditioning, it may be time to consider the possibility that conditioning in the intact human or animal is not a simple task that is carried out by an isolated independent system. Rather, it appears to be a cognitively mediated task that depends critically on awareness.

In fact, there is existing evidence that brain regions which are thought to encode declarative knowledge modulate delay eyeblink conditioning. In rabbits, hippocampal activity is associated with eyeblink CRs in both delay and trace procedures (e.g., Green and Arenos 2007; Nokia et al. 2008). In human neuroimaging studies, hippocampal activity is associated with delay eyeblink conditioning (Blaxton et al. 1996). In both animals and humans, disruption of normal activity in the hippocampus and forebrain structures interferes with delay eyeblink conditioning (Moore et al. 1976; Solomon et al. 1993; Myers et al. 2001; Allen et al. 2002). The challenge for neural models of learning and memory will be to specify the nature of the interaction between cortical systems and subcortical systems, such as the cerebellum and amygdala, that give rise to the coordinated behavioral performance we observe. A good model for such a coordinated system is provided by Squire's more recent analysis of the cooperative neural network underlying recollection and familiarity, aspects of memory that were previously considered to have distinct neural underpinnings (Squire et al. 2007).

\section{Acknowledgments}

This research was supported by grant DP0877407 and DP1096437 from the Australian Research Council.

\section{References}

Allen MT, Padilla Y, Gluck MA. 2002. Ibotenic acid lesions of the medial septum retard delay eyeblink conditioning in rabbits (Oryctolagus cuniculus). Behav Neurosci 116: 733-738.

Benish WA, Grant DA. 1980. Subject awareness in differential classical conditioning. Bull Psychon Soc 15: 431-432.

Blaxton TA, Zeffiro TA, Gabrieli JDE, Bookheimer SY, Carrillo MC, Theodore WH, Disterhoft JF. 1996. Functional mapping of human learning: A positron emission tomography activation study of eyeblink conditioning. J Neurosci 16: 4032-4040.

Clark RE, Squire LR. 1998. Classical conditioning and brain systems: The role of awareness. Science 280: 77-81.

Clark RE, Squire LR. 1999. Human eyeblink classical conditioning: Effects of manipulating awareness of the stimulus contingencies. Psychol Sci 10: $14-18$.

Dawson ME, Biferno MA. 1973. Concurrent measurement of awareness and electrodermal classical conditioning. J Exp Psychol 101: 55-62.

Eichenbaum H, Cohen NJ. 2001. From conditioning to conscious recollection: Memory systems of the brain. Oxford University Press, New York.

Green JT, Arenos JD. 2007. Hippocampal and cerebellar single-unit activity during delay and trace eyeblink conditioning in the rat. Neurobiol Learn Mem 87: 269-284.

Knuttinen MG, Power JM, Preston AR, Disterhoft JF. 2001. Awareness in classical differential eyeblink conditioning in young and aging humans. Behav Neurosci 115: 747-757.

Lovibond PF, Shanks DR. 2002. The role of awareness in Pavlovian conditioning: Empirical evidence and theoretical implications. J Exp Psychol Anim Behav Process 28: 3-26.
Lovibond PF, Liu JCJ, Weidemann G, Mitchell CJ. 2011. Awareness is necessary for differential trace and delay eyeblink conditioning in humans. Biol Psychol 87: 393-400.

Manns JR, Clark RE, Squire LR. 2000a. Awareness predicts the magnitude of single-cue trace eyeblink conditioning. Hippocampus 10: 181-186.

Manns JR, Clark RE, Squire LR. 2000b. Parallel acquisition of awareness and trace eyeblink classical conditioning. Learn Mem 7: 267-272.

Manns JR, Clark RE, Squire LR. 2001. Single-cue delay eyeblink conditioning is unrelated to awareness. Cogn Affect Behav Neurosci 1: $192-198$.

Manns JR, Clark RE, Squire LR. 2002. Standard delay eyeblink classical conditioning is independent of awareness. J Exp Psychol Anim Behav Process 28: $32-37$.

Mitchell CJ, De Houwer J, Lovibond PF. 2009. The propositional nature of human associative learning. Behav Brain Sci 32: 183-198.

Moore JW, Goodell NA, Solomon PR. 1976. Central cholinergic blockade by scopolamine and habituation, classical conditioning, and latent inhibition of the rabbit's nictitating membrane response. Physiol Psychol 4: 395-399.

Myers CE, DeLuca J, Schultheis MT, Schnirman GM, Ermita BR, Diamond B, Warren SG, Gluck MA. 2001. Impaired delay eyeblink classical conditioning in individuals with anterograde amnesia resulting from anterior communicating artery aneurysm rupture. Behav Neurosci 115: $560-570$.

Nelson MN, Ross LE. 1974. Effects of masking tasks on differential eyelid conditioning: A distinction between knowledge of stimulus contingencies and attentional or cognitive activities involving them. J Exp Psychol 102: 1-9.

Nokia MS, Penttonen M, Korhonen T, Wikgren J. 2008. Hippocampal $\theta(3-8 \mathrm{~Hz})$ activity during classical eyeblink conditioning in rabbits. Neurobiol Learn Mem 90: 62-70.

Papka M, Ivry RB, Woodruff-Pak DS. 1997. Eyeblink classical conditioning and awareness revisited. Psychol Sci 8: 404-408.

Perry LC, Grant DA, Schwartz M. 1977. Effects of noun imagery and awareness of the discriminative cue upon differential eyelid conditioning to grammatical and ungrammatical phrases. Mem Cogn 5: $423-429$

Perry LC, Brown RMD, Perry DG. 1979. Interactive effects of cognitive involvement and response topography upon differential eyelid conditioning to conceptual discriminanda. Am J Psychol 92: 401-412.

Ross LE. 1971. Cognitive factors in conditioning: The use of masking tasks in eyelid conditioning. In Essays in neobehaviorism: A memorial volume to Kenneth W. Spence (ed. Kendler HH, Spence JT), pp. 161-185. Appleton-Century-Crofts, New York.

Schacter DL, Tulving E. 1994. Memory systems 1994. MIT Press, Cambridge, MA.

Smith CN, Clark RE, Manns JR, Squire LR. 2005. Acquisition of differential delay eyeblink classical conditioning is independent of awareness. Behav Neurosci 119: 78-86.

Solomon PR, Groccia-Ellison ME, Flynn D, Mirak J, Edwards KR, Dunehew A, Stanton ME. 1993. Disruption of human eyeblink conditioning after central cholinergic blockade with scopolamine. Behav Neurosci 107: 271-279.

Squire LR. 1987. Memory and brain. Oxford University Press, New York.

Squire LR. 1994. Declarative and nondeclarative memory: Multiple brain systems supporting learning and memory. In Memory systems (ed. Schacter DL, Tulving E), pp. 203-231. MIT Press, Cambridge, MA.

Squire LR, Wixted JT, Clark RE. 2007. Recognition memory and the medial temporal lobe: A new perspective. Nat Rev Neurosci 8: $872-883$.

Taylor WA. 2000. Change-point analysis: A powerful new tool for detecting changes. http://www.variation.com/cpa/tech/changepoint.html.

Weidemann G, Antees C. 2012. Parallel acquisition of awareness and differential delay eyeblink conditioning. Learn Mem 19: 201-210.

Received December 9, 2012; accepted in revised form April 26, 2013. 


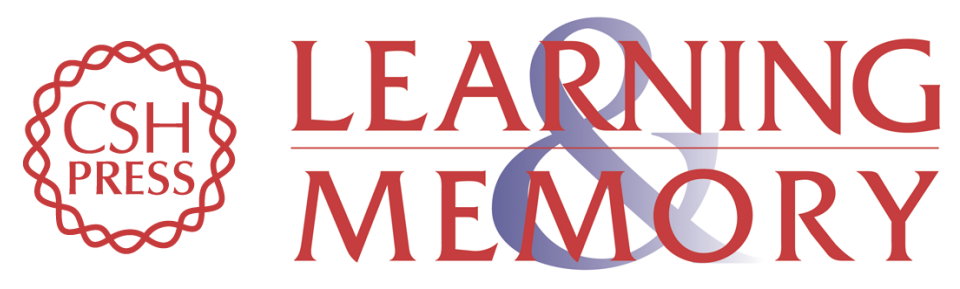

\section{The role of contingency awareness in single-cue human eyeblink conditioning}

Gabrielle Weidemann, Erin Best, Jessica C. Lee, et al.

Learn. Mem. 2013, 20:

Access the most recent version at doi:10.1101/Im.029975.112

\section{Supplemental http://learnmem.cshlp.org/content/suppl/2013/06/17/20.7.363.DC1 Material}

References This article cites 26 articles, 4 of which can be accessed free at: http://learnmem.cshlp.org/content/20/7/363.full.html\#ref-list-1

Creative This article is distributed exclusively by Cold Spring Harbor Laboratory Press for the Commons first 12 months after the full-issue publication date (see

License http://learnmem.cshlp.org/site/misc/terms.xhtml). After 12 months, it is available under a Creative Commons License (Attribution-NonCommercial 3.0 Unported), as described at http://creativecommons.org/licenses/by-nc/3.0/.

Email Alerting Receive free email alerts when new articles cite this article - sign up in the box at the Service top right corner of the article or click here. 